\title{
IL-7 receptor $\alpha$ expressing $B$ cells act proinflammatory in collagen-induced arthritis and are inhibited by sympathetic neurotransmitters
}

\author{
Georg Pongratz, ${ }^{1}$ Judith M Anthofer, ${ }^{1}$ Madlen Melzer, ${ }^{1}$ Sven Anders, ${ }^{2}$ \\ Susanne Grässel, ${ }^{3}$ Rainer H Straub ${ }^{1}$
}

\begin{abstract}
Handling editor Tore K Kvien
${ }^{1}$ Laboratory of Experimental Rheumatology and Neuroendocrine Immunology, Department of Internal Medicine I, University Hospital Regensburg, Regensburg, Germany

${ }^{2}$ Deptartment of Orthopaedic Surgery, University Hospital Regensburg, Asklepios Clinic Bad Abbach, Bad Abbach, Germany

${ }^{3}$ Experimental Orthopedics, ZMB/BioPark1; University Hospital Regensburg, Regensburg, Germany
\end{abstract}

\section{Correspondence to}

Dr Georg Pongratz, Laboratory of Exp. Rheumatology and Neuroendocrine Immunology, Department of Internal Medicine I, University Hospital Regensburg,

Regensburg 93042, Germany; georg.pongratz@klinik. uni-regensburg.de

Accepted 24 February 2013 Published Online First 16 March 2013
To cite: Pongratz $\mathrm{G}$ Anthofer JM, Melzer M, et al. Ann Rheum Dis 2014;73:306-312.

\section{ABSTRACT}

Objectives The sympathetic nervous system (SNS) as well as the interleukin (IL)-7/IL-7 receptor (IL-7R) system play a role in the pathogenesis of arthritis. However, the target cells and mechanisms involved are not fully resolved. The goal of this study was to determine if $B$ cells are influenced by IL-7 and to investigate the possible interplay between the SNS and the IL-7/IL-7R system on B cells in arthritis.

Methods Collagen type Il-induced arthritis (CIA) in DBA1 mice. ELISA to determine specific anti-CII antibodies. Fluorescence activated cell sorting (FACS) analysis to determine IL-7R + cells and intracellular phosphorylated signal transducer and activator of transcription 5 (pSTAT5). Immunohistochemistry to show IL-7R+B cells in rheumatoid arthritis (RA) and osteoarthritis (OA) synovial tissue.

Results IL-7 stimulated IL-7R+ mature B cells act proinflammatory (increased clinical score, increased anticollagen type II antibodies) after cell transfer in CIA. The sympathetic neurotransmitter norepinephrine abrogates this effect. Expression of IL-7R $\alpha$ is increased when $B$ cells are activated (anti-CD40 or lipopolysaccharide) in vitro and stimulating the IL-7R induces intracellular accumulation of PSTAT5. $\alpha$-And $\beta$-adrenergic agonists show no influence on expression levels of IL-7R on activated B cells; however, intracellular IL-7R downstream signalling is abrogated via the $\beta 2$-adreonceptor ( $\beta 2 A R$ ) agonist terbutaline. IL-7R and $\beta 2 A R$ are also expressed on $B$ cells in synovial tissue from RA and OA patients.

Conclusions These data indicate that IL7R+ B cells have a proinflammatory role in arthritis which can be inhibited by the sympathetic neurotransmitter norepinephrine via inhibition of IL-7R signalling.

\section{INTRODUCTION}

Interleukin (IL)-7 is a cytokine involved in the regulation of B cell development and survival. ${ }^{1}{ }^{2}$ In later stages of B cell development, the role played by IL-7 is more controversial and reports showing expression of the receptor on mature B cells are scarce. ${ }^{3-6}$

The IL-7 receptor (IL-7R) is heterodimeric, consisting of IL-7R $\alpha$ chain (IL-7R $\alpha$, CD127) and the common $\gamma$ chain; $^{7}$ the latter is also a component of the IL-2-, IL-4-, IL-9-, IL-15- and IL-21 receptor. ${ }^{8}$ Dimerisation of the IL-7R $\alpha$ chain and the common $\gamma$ chain mainly activates a signal transducer and activator of transcription 5 (STAT 5)-dependent pathways via Janus kinase 1 and 3 (reviewed in ${ }^{9}$ ).

In arthritis, IL-7 might play an important role ${ }^{10}$ since IL-7 in synovial fluid and serum from rheumatoid arthritis (RA) patients was detected at a higher level as compared with osteoarthritis (OA) patients and correlated in serum with $\mathrm{C}$ reactive protein. ${ }^{11} 12 \mathrm{IL}-7$ is produced in RA synovium ${ }^{13}{ }^{14}$ by fibroblast-like synoviocytes ${ }^{15}$ macrophages, fibroblasts, endothelial cells ${ }^{11}$ and nurse-like synovial cells that express costimulatory molecules, and is capable of rescuing B cells from apoptosis. ${ }^{15} 16$ Furthermore, IL-7/IL-7R pathway-related genes were increased in RA synovial tissue containing ectopic lymphoid structures with local activation of B cells. ${ }^{17}$ Mice treated with IL-7 during collagen type II-induced arthritis (CIA) showed an expansion of the $\mathrm{B}$ and $\mathrm{T}$ cell pool and increased joint destruction. ${ }^{18}$ Expression of IL-7R on CD19 B cells, CD4 T cells and CD14 monocytes in RA synovial tissue was reported recently and therapeutic blockade of IL-7 signalling in RA or CIA has therapeutic potential by inhibiting $\mathrm{T}$ cells. Recently, it has been shown that RA fibroblasts and to a lesser extent CD4 T cells, in contrast to CD8 T and B cells, express a soluble form of the IL-7R, which can counteract the action of IL-7 in the inflamed synovium. $^{6}$

The sympathetic nervous system (SNS) modulates both arthritis severity ${ }^{19}{ }^{20}$ and B cell function. ${ }^{21} 22$ The SNS supports inflammation in the initiation phase and suppresses inflammation in the late phase of CIA. ${ }^{19}{ }^{23}$ The proinflammatory effect during the initiation phase might be mediated via promoting $\mathrm{T}$ cells. $^{23}{ }^{24}$ In the late phase of CIA the SNS increases IL-10 production and anti-inflammatory properties of $\mathrm{B}$ cells ${ }^{20}$ in addition to the occurrence of possible antiinflammatory catecholamine-producing cells. ${ }^{25}$ The influence of the SNS on B cells during initiation of arthritis is less clear. It has been shown in several reports that B cell response following T-dependent antigens is impaired in the absence of sympathetic stimuli. $^{21} 22$ One could speculate that increased T-dependent antibody production promotes inflammation in the initiation phase.

The goals of this study were to determine the role of the IL-7/IL-7R system on B cells in arthritis and to investigate the possible interplay between the SNS and the IL-7/IL-7R system on B cells in the context of arthritis.

\section{MATERIAL AND METHODS}

\section{Animals, induction of arthritis} and arthritis scoring

Male DBA/1 mice (6-8 weeks, Elevage Janvier, Le Genest St Isle, France) were fed standard chow and 
water ad libitum and kept at a $12 \mathrm{~h}$ light-dark cycle. Experiments were conducted according to institutional and governmental regulations for animal use (Government of the Oberpfalz AZ 54-2531.1-24/06).

Experimental arthritis was induced in DBA/1 mice, as previously described ${ }^{20}$ by intradermal injection with $100 \mu \mathrm{g}$ of bovine type II collagen (CII, Chondrex, Redmond, Washington, USA) and Freund's complete adjuvant (CFA, Sigma). Clinical scoring points were assigned in a blinded manner as described previously. ${ }^{27}$ A score of 0 (no swelling), 1 (light swelling) or 2 (strong swelling) was determined for four toes at each paw, four paws and ankle/wrist joints with a maximum of 48 points.

\section{Determination of specific anticollagen type II antibodies}

Venous blood was obtained from the tail vein at indicated time points. Serum samples were stored at $-80^{\circ} \mathrm{C}$ until analysis. Anticollagen type II antibodies were determined using commercially available ELISA kits (MD Biosciences GmbH, Zürich, Switzerland).

\section{$B$ cell in vitro culture}

Mature splenic B cells were isolated using magnetic bead cell sorting (MACS, B cell isolation kit, Miltenyi Biotec, Germany). After isolation, $>96 \%$ were CD19/CD20 B cells. After resuspending in complete RPMI (cRPMI: RPMI 1640, $25 \mathrm{mM}$ HEPES, pH 7.4, 5\% fetal calf serum, $30 \mu \mathrm{M}$ mercaptoethanol, $0.57 \mathrm{mM}$ ascorbic acid, $100 \mathrm{units} / \mathrm{ml}$ penicillin, $100 \mu \mathrm{g} / \mathrm{ml}$ streptomycin (all from Sigma, Munich, Germany)) containing anti-CD40 $(5 \mu \mathrm{g} / \mathrm{ml}$, clone: FGK 45.5, Miltenyi Biotec, Bergisch-Gladbach, Germany) and functional grade IL-4 (1 ng/ $\mathrm{ml}$, eBioscience), cells were cultured in the presence or absence of norepinephrine, $\beta 2$-adreonceptor ( $\beta 2 \mathrm{AR}$ ) specific agonist terbutaline, $\alpha 1$-specific agonist phenylephrine, $\alpha 2$-specific agonist clonidin or cortisol as indicated.

\section{Treatment of early arthritis mice with cultured B cells}

B cells were cultured for 5 days in 6 -well plates at $2.5 \times 10^{6} / \mathrm{ml}$ in the presence or absence of norepinephrine. After 5 days, recombinant murine IL-7 (R\&D Systems, $20 \mathrm{ng} / \mathrm{ml}$ ) or vehicle was added to the cells for $30 \mathrm{~min}$. After the incubation, cells were washed five times, resuspended in phosphate buffered saline (PBS) and used for treatment of CIA mice at day $19\left(1.5 \times 10^{6} \mathrm{~B}\right.$ cell/100 $\mu$ l intravenous).

\section{Analysis of IL-7R $\alpha$ expression on murine B cells}

Before and after 5 days of culture, FACS was performed to determine expression of IL-7R $\alpha$ (CD127) on CD19 B cells. B cells were stained with FITC-labelled rat anti-mouse CD19 and PE-labelled rat antimouse CD127 (Clone A7R34, eBioscience, Frankfurt, Germany) or respective isotype control for $15 \mathrm{~min}$ at $4^{\circ} \mathrm{C}$ in the dark. Cells were also stained with 7-AAD to exclude dead cells. FACS analysis was performed on a FACS Calibur (Becton Dickinson Immunocytometry Systems, San Jose, California, USA). Data were analysed with FlowJo Software (V.7.2.4., Tree Star Inc., Oregon, USA).

\section{Intracellular measurement of phosphorylated STAT5}

After 5 days of culture, B cells were analysed for the intracellular amount of pSTAT5 at time point 0,10 and $30 \mathrm{~min}$ following exposure to IL-7 (20 ng/ml, R\&D Systems). Cells were fixed (1.5\% formaldehyde) and permeabilised with methanol according to a published method. ${ }^{28} \mathrm{~B}$ cells were stained with monoclonal rabbit antiphospho-STAT5A/B (Tyr694/699, Clone: A11W, Millipore, Schwalbach, Germany) or respective isotype control for $30 \mathrm{~min}$ at $4^{\circ} \mathrm{C}$. Biotinylated, polyclonal goat antirabbit $\mathrm{IgG}$
(Dako, Hamburg, Germany) was used as secondary antibody. FACS was performed after staining with PE-labelled streptavidin. Samples were also stained with secondary antibody and PE-streptavidin only to exclude unspecific binding.

\section{Immunhistochemical analysis of IL-7R $\alpha+B$ cells in synovial tissue}

Synovial tissue from RA and OA patients obtained during knee replacement surgery was prepared for histological studies as described. $^{29}$ All patients gave written consent. The study was approved by the Ethics Committee of the University of Regensburg. Cryosections $(5 \mu \mathrm{m})$ were stained with antibodies against CD19 (polyclonal, rabbit antihuman CD19, $5 \mu \mathrm{g} / \mathrm{ml}$, Santa Cruz, Heidelberg, Germany), IL-7R $\alpha$ (monoclonal, Clone: 40131, mouse antihuman CD127, Dilution: 1:100, Sigma-Aldrich $\mathrm{GmbH}$, Taufkirchen, Germany) or $\beta 2 \mathrm{AR}$ (polyclonal, rabbit antihuman B2AR, 1:200, Biozol, Eching, Germany) overnight at $4^{\circ} \mathrm{C}$. Secondary antibodies coupled to AlexaFluor 546 or AlexaFluor 488 (polyclonal, goat vs rabbit, goat vs mouse, or donkey vs rat. Invitrogen, Karlsruhe, Germany) were applied for $90 \mathrm{~min}$ at $21^{\circ} \mathrm{C}$. Slides were blocked with PBS containing 10\% fetal bovine serum, $10 \%$ bovine serum albumin, and $10 \%$ donkey serum, or $10 \%$ goat serum for $45 \mathrm{~min}$ at $21^{\circ} \mathrm{C}$. After $4^{\prime}$-6-diamidino-2-phenylindole (DAPI; Roche, Mannheim, Germany) staining, slides were covered with fluorescence mounting medium (DAKO, Hamburg, Germany) and stored at $4^{\circ} \mathrm{C}$ until. Control stainings with the primary or secondary antibody alone or respective isotype controls were negative.

\section{FACS analysis of IL-7R $\alpha+B$ cells in synovial tissue}

Mixed synoviocytes were isolated from RA and OA tissue as described before. ${ }^{29}$ Synoviocytes were stained $\left(15 \mathrm{~min}, 4^{\circ} \mathrm{C}\right)$ with PE-labelled mouse antihuman CD127 (Clone: hIL-7R-M21, BD Pharmingen, Heidelberg) and counterstained with FITC-labelled mouse antihuman CD19 (BD Pharmingen, Heidelberg) or mouse antihuman CD20 (MACS, Miltenyi Biotec, Bergisch-Gladbach), respectively. Respective isotype control antibodies were used as a control for unspecific binding. Cells were stained with 7-AAD (BD Pharmingen, Heidelberg) to exclude dead cells.

\section{Statistical analysis}

The non-parametric Mann-Whitney test was used to compare two groups, and ANOVA with post hoc tests was used to compare multiple groups. All analyses were conducted using Sigma Plot for Windows (V.11; Systat software Inc). p Values $<0.05$ were considered significant.

\section{RESULTS}

\section{Short term exposure to IL-7 increases proinflammatory} action of $B$ cells in CIA

A pathogenetic contribution of the IL-7/IL7R $\alpha$ system in RA but also collagen-induced arthritis was suggested before. ${ }^{3} 61730$ To determine the role of IL-7R $\alpha$ expressing B cells in CIA, B cells were activated with anti-CD40/IL-4 for 5 days and exposed to IL-7 or vehicle for 30 min before B cells were injected intravenously into DBA1 mice at day 19 after immunisation. Mice receiving B cells stimulated with IL-7 demonstrated a significant increase in clinical score (figure $1 \mathrm{~A}$, white circles vs white triangles) and anti-CII antibodies (figure $1 \mathrm{~B}$, white circles vs white triangles) as compared with control.

\section{Norepinephrine influences IL-7-induced proinflammatory B cell activity}

The SNS acts proinflammatory during the induction phase of $\mathrm{CIA}^{31}$ and augments T-dependent B cell responses. ${ }^{21} 2232$ To 
A

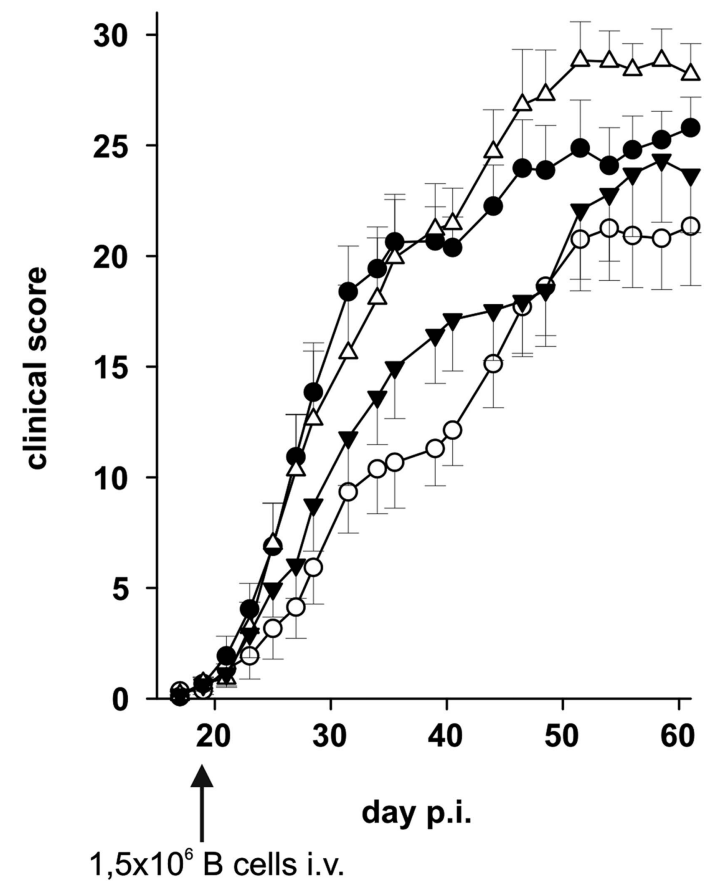

Activation of $\longrightarrow$ stimulation $\mathrm{B}$ cells $(5 \mathrm{~d}) \longrightarrow$ for 30 minutes

B

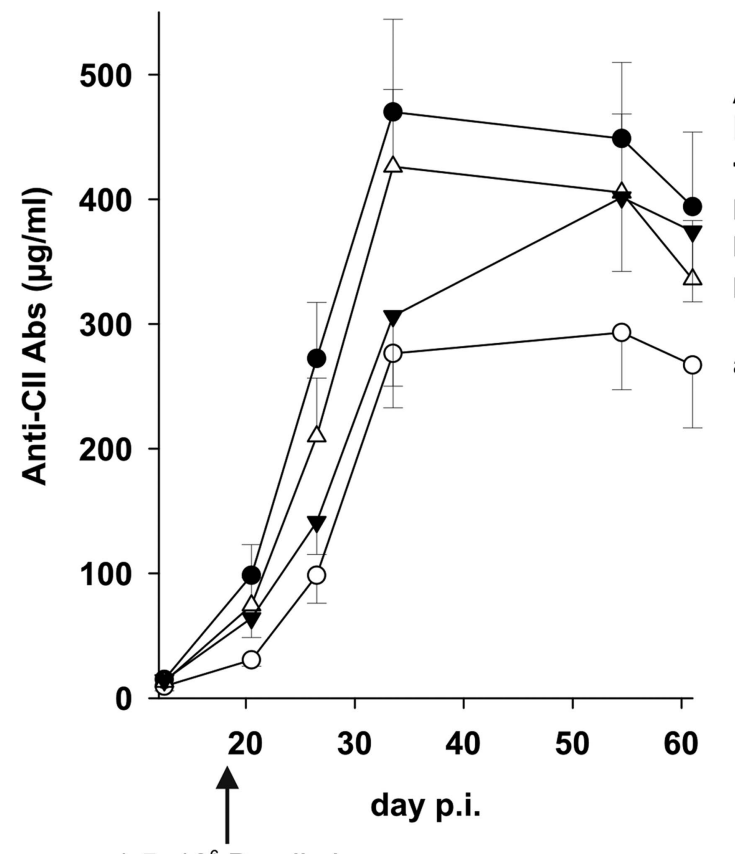

Activation of $\longrightarrow$ stimulation B cells $(5 \mathrm{~d}) \longrightarrow$ for 30 minutes \begin{tabular}{l|l}
$\mathrm{BL}+\mathrm{Nor}$ & $\mathrm{PBS}$
\end{tabular} $\begin{array}{ll}\mathrm{BL}+\mathrm{Nor} & \mathrm{IL}-7\end{array}$ $\begin{array}{lll}B L & \mathrm{IL}-7\end{array}$ anti-CD40/IL-4 (BL)

$1,5 \times 10^{6} \mathrm{~B}$ cells i.v.

Figure 1 Proinflammatory action of IL-7R+B cells in collagen type II-induced arthritis (CIA) is diminished by the sympathetic neurotransmitter norepinephrine. Following in vitro activation of $B$ cells with anti-CD40/IL-4 (BL, white circle, white triangle) in the absence (white symbols) or presence (black symbols) of norepinephrine (Nor, $10^{-6} \mathrm{M}$ ) and after stimulating the cells with IL-7 (white and black triangles) or PBS (white and black circles) as indicated, $1.5 \times 10^{6} \mathrm{~B}$ cells were transferred intravenously to CIA mice on day 19 postimmunisation (arrow). Clinical score (A) was recorded and concentration of anti-CII antibodies (Abs) in serum (B) was determined at indicated time points. The symbols represent the mean of two independent experiments with six animals in each group. ANOVA (general linear model) showed the different treatments as a significant source of variation for clinical score $(A, p<0.001)$ and anti-Cll antibody serum concentration $(B, p<0.001)$, respectively. Post hoc analysis (Holm-Sidak) revealed a significant increase as compared with the control group (anti-CD40/IL-4+PBS) for clinical score (A): BL+IL-7 (days 28-61), BL+Nor (days $27-44)$ and anti-CII Abs serum levels: BL+Nor $(p<0.001), B L+I L-7(p=0.002)$ and BL+Nor+IL-7 $(p=0.026)$. Error bars represent the SEM. Anti-CII Abs, anticollagen type II antibodies; i.v., intravenous; p.i., postimmunisation.

determine if norepinephrine further increases the proinflammatory potential of IL-7 stimulated B cells, we activated B cells in the presence of norepinephrine.
Surprisingly, treatment of mice with IL-7 stimulated B cells activated in the presence of norepinephrine did not result in increased severity of arthritis (figure 1A, white circles vs black triangles) and 
delayed the increase in specific CII antibody production (figure $1 \mathrm{~B}$, black triangles).

This suggests that the presence of norepinephrine during activation of B cells renders B cells unresponsive to proinflammatory effects of IL-7. On the contrary, an IL-7 stimulus on B cells pretreated with norepinephrine (figure $1 \mathrm{~A}$, black triangles) leads to anti-inflammatory effects, with decreased arthritis severity as compared with treatment with norepinephrine only exposed B cells (figure 1A, black circles). Therefore, norepinephrine inhibits and reverses the proinflammatory effect of IL-7 on B cells in CIA.

In vitro culture induces IL-7R $\alpha$ expression on mature B cells Since the expression of the IL-7R $\alpha$ is a prerequisite for $\mathrm{B}$ cells to react to IL-7, we determined whether naive splenic $B$ cells from DBA1 mice increase IL-7R $\alpha$ upon activation in vitro.
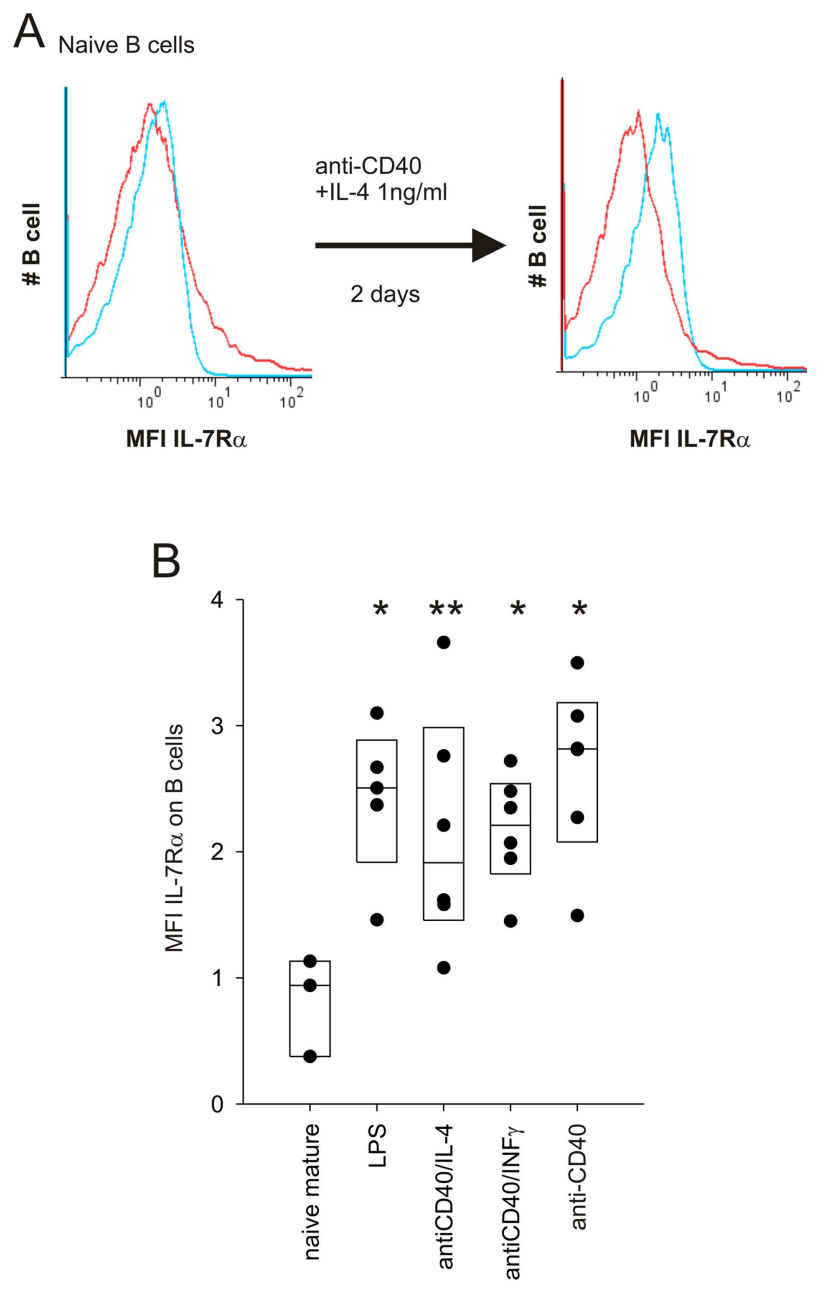

Figure 2 In vitro activation of splenic naive $B$ cells leads to increased expression of IL-7 receptor $\alpha$ (IL-7R $\alpha$ ). (A) Representative FACS histogram showing increased expression of IL-7R $\alpha$ on B cells activated in the presence of anti-CD40 and IL-4 for 2 days. Red line: Isotype control, blue line: IL-7R $\alpha$ signal. Mean fluorescence intensity (MFI). (B) Increase of IL-7R $\alpha$ on B cells activated with different stimuli. Each dot represents IL-7R MFI on gated CD19+ B cells after subtraction of the MFI of the respective isotype control. $p$ Value was determined by ANOVA (overall difference between groups: $p=0.015$ ) and post hoc analysis (Bonferroni). ${ }^{*} p<0.05,{ }^{* *} p<0.01$ as compared with unstimulated $B$ cells (naive mature). Results are presented as box plots, horizontal lines represent the median value. IL-4, interleukin-4; INF $\gamma$, interferon- $\gamma$; LPS, lipopolysaccharide. $\mathrm{N}>3$.
Isolated naive $B$ cells were cultured for 2 days in the presence or absence of different $\mathrm{B}$ cell activating stimuli (figure $2 \mathrm{~A}$ ). The activation of B cells via CD40 independent of IL- 4 or INF- $\gamma$, respectively, increased IL-7R $\alpha$ expression on splenic $B$ cells from DBA1 mice (figure 2B). Additionally, lipopolysaccharide, the activation signal via TLR4, also increased IL-7R $\alpha$ expression (figure 2B). These data confirm increased expression of IL-7R on $\mathrm{B}$ cells activated in vitro.
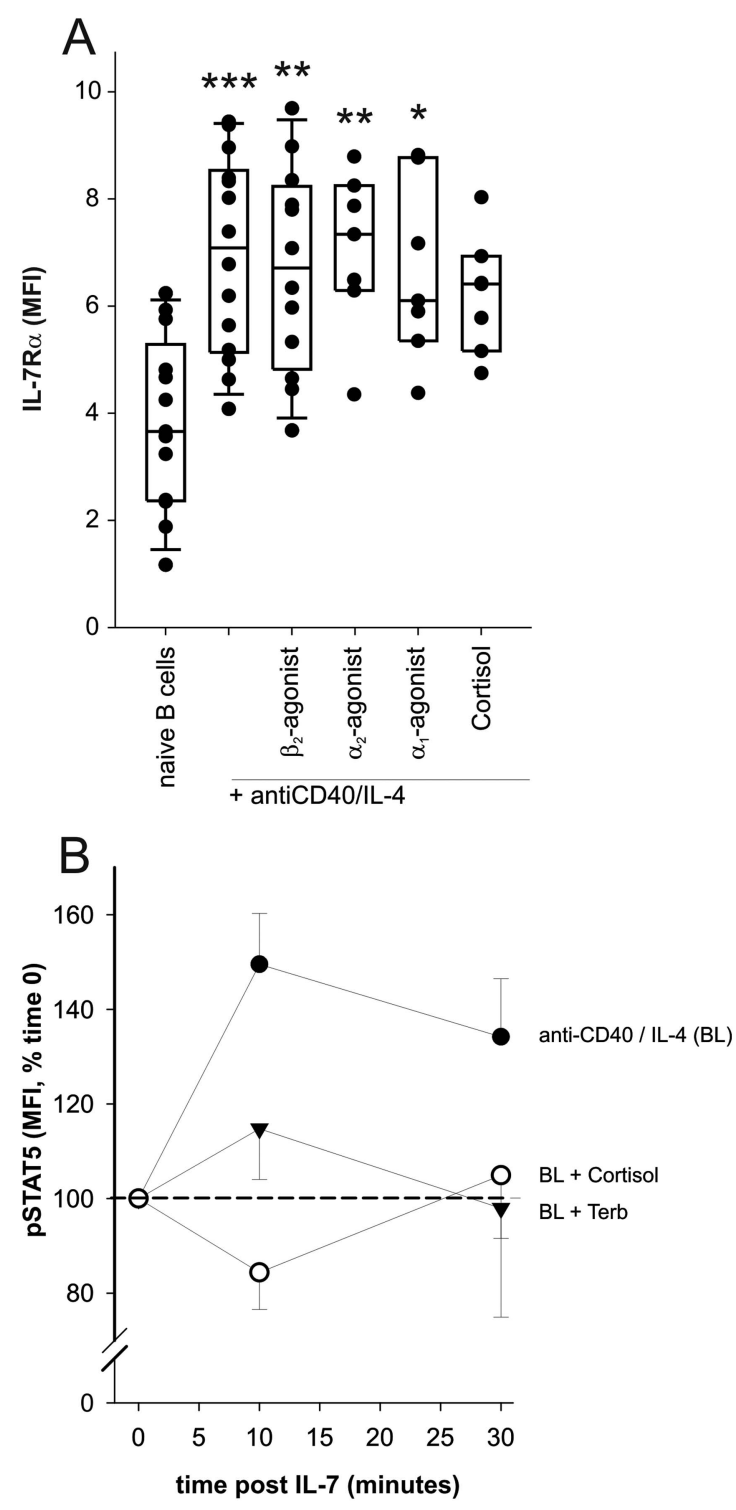

Figure 3 Adrenergic influence on IL-7R expression and signalling in $B$ cells. (A) Each dot represents the mean fluorescence intensity of IL-7R expressed on B cells activated with anti-CD40/IL-4 (BL) in the presence or absence of different adrenergic stimuli ( $\beta 2$-adrenoceptor specific agonist terbutaline (Terb, $\left.10^{-6} \mathrm{M}\right), \alpha 1$-specific agonist phenylephrine $\left(5 \times 10^{-6} \mathrm{M}\right), \alpha 2$-specific agonist clonidin $\left.\left(5 \times 10^{-6} \mathrm{M}\right)\right)$ or cortisol $\left(10^{-6} \mathrm{M}\right)$. Results are presented as box plots, horizontal lines represent the median value. $p$ Values were determined by ANOVA followed by Bonferroni post hoc analysis. ${ }^{*} p<0.05,{ }^{*} p<0.01,{ }^{* * *} p<0.001$ as compared with unstimulated B cells (naive B cells). (B) Intracellular FACS analysis of accumulation of pSTAT5 over time (minutes) following IL-7 exposure of activated B cells. Error bars represent the SEM. Six ( $\mathrm{BL}$ and $\mathrm{BL}+\mathrm{Terb})$ and four (BL+Cortisol) independent experiments were performed. $p$ Values were determined by ANOVA (overall treatment: $\mathrm{p}=0.008$ ) and post hoc analysis (Student-Newman-Keuls, BL vs $B L+$ Terb: $p=0.015 ; B L$ vs $B L+C o r t: ~ p=0.012 ; B L+T e r b$ vs $B L+C o r t: ~ p=0.457)$. 


\section{Cortisol but not adrenergic stimuli inhibit activation-induced IL-7R $\alpha$ expression on mature B cells}

One reason for the dampened IL-7 response following activation of $\mathrm{B}$ cells in the presence of norepinephrine might be a change in IL-7R $\alpha$ expression. Therefore, B cells were activated in the presence of adrenergic stimuli as indicated (figure $3 \mathrm{~A}$ ). Additionally, B cells were activated in the presence of cortisol, according to a report showing an increase of IL-7R $\alpha$ following cortisol exposure. ${ }^{5}$

Neither of the adrenoceptor agonists induced a significant decrease of IL-7R $\alpha$ expression on B cells as compared with anti-CD40/IL-4 activated B cells (figure 3A). Unexpectedly, expression levels of IL-7R $\alpha$ on cortisol treated $B$ cells did not change as compared with naive $\mathrm{B}$ cells. These results suggest that adrenergic stimuli do not influence and cortisol slightly inhibits IL-7R $\alpha$ re-expression on activated B cells.

\section{Activation of $B$ cells in the presence of $\beta 2 A R$ agonist hinders IL-7R $\alpha$ downstream signalling}

Next, the hypothesis was tested whether adrenoceptor stimulation alters phosphorylation of STAT5, which is the major downstream signal following IL-7R activation. ${ }^{33} \mathrm{~B}$ cells were activated in the presence or absence of different adrenoceptor agonists or cortisol, as indicated (figure 3B).

The generation of pSTAT5 accumulating after IL-7 exposure was inhibited in activated $\mathrm{B}$ cells by pretreatment with the $\beta 2 \mathrm{AR}$ agonist terbutaline or cortisol (figure 3B). Pretreatment with $\alpha$-adrenoceptor agonists did not show this inhibition (data not shown). These data suggest that $\beta 2 \mathrm{AR}$ stimulation during activation renders B cells unresponsive to IL-7 due to inhibiting phosphorylation of STAT5. The data also show that IL-7R re-expressed on mature $\mathrm{B}$ cells are functional, leading to an increase in pSTAT5 following IL-7 exposure.

\section{IL-7R $\alpha$ and $\beta 2 A R$ is expressed on B cells in synovial tissue of RA and OA patients}

Immunohistochemistry shows that IL-7R $\alpha$ is expressed on CD19+ synovial B cells (figure 4A). The absolute number of CD19/IL-7R $\alpha+$ B cells is significantly elevated in synovial tissue from RA patients as compared with OA (figure 4B, $p=0.03$ ), which also confirms previous results. ${ }^{3}$ However, FACS analysis of mixed synoviocytes revealed that the percentage of CD19 or CD20 B cells expressing IL-7R $\alpha$ is not different between OA and RA (figure 4C). This result suggests that IL-7R $\alpha+B$ cells
A
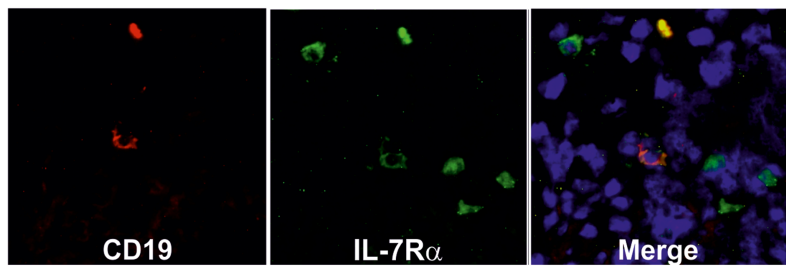

C

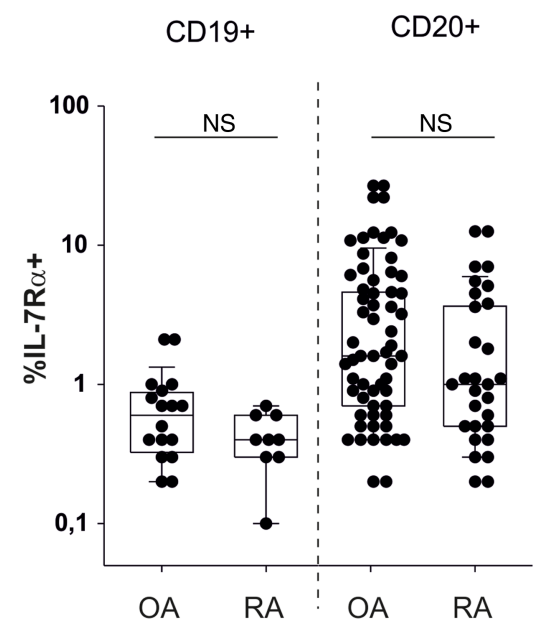

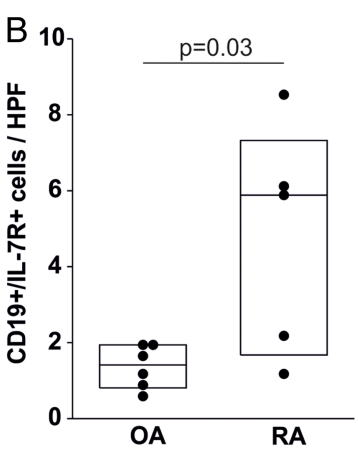

D

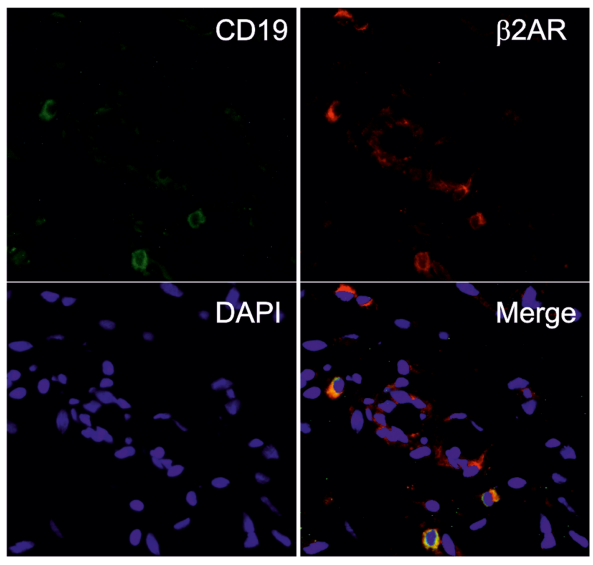

Figure 4 B cells express IL-7 receptor $\alpha$ in synovial tissue from osteoarthritis (OA) and rheumatoid arthritis (RA) patients. (A) Representative immunohistochemistry showing CD19 or IL-7R $\alpha+$ cells in synovial tissue as indicated at the bottom of each image. The right image represents a merge of the two images to the left showing a double positive cell additionally stained with $4^{\prime}-6$-diamidino-2-phenylindole (DAPI) for DNA staining (blue colour). (B) Absolute number of IL-7R $\alpha+/ C D 19$ B cells in synovial tissue from RA $(n=5)$ and OA $(n=6)$ patients. Each dot represents results of one patient with the mean number of IL-7R $\alpha+/ C D 19$ B cells averaged from counting 17 high power fields (400x). $p$ Value was determined by Mann-Whitney test. Results are presented as box plots, horizontal lines represent the median value. (C) FACS analysis of mixed synoviocytes. Each dot represents the percentage of IL-7R $\alpha+$ and CD19 (left side), or IL-7R $\alpha+$ and CD20 (right side) cells isolated from synovial tissue of RA (CD19: $n=9 ; C D 20: n=27$ ) or OA (CD19: $n=16 ; C D 20: n=57)$ patients, respectively. Results are presented as box plots, horizontal lines represent the median value. NS, not significant in Mann-Whitney test. (D) Representative immunohistochemistry from RA tissue showing CD19, $\beta 2$ adrenoceptor+, DAPI or a merged image (Merge), as indicated. 
are not over-represented in RA synovium but might occur in every inflammatory infiltrate.

Due to the interplay between $\beta 2 \mathrm{AR}$ and the IL-7/IL-7R system evident in the CIA model, we confirmed that this interaction might also take place in the human system by showing that $\beta 2 \mathrm{AR}$ is expressed on synovial $\mathrm{B}$ cells from OA (data not shown) and RA patients (figure 4D).

\section{DISCUSSION}

The IL-7/IL-7R system has been suggested to be involved in the regulation of autoimmune inflammation. ${ }^{34}$ To our knowledge, this is the first report directly demonstrating a role for IL-7R $\alpha$ expressing B cells in CIA. Transfer of activated, IL-7 stimulated $\mathrm{B}$ cells into CIA aggravates arthritis and increases production of specific anti-CII antibodies, which might be one mechanism to explain the propagation of arthritis, because it has been shown before that anti-CII antibodies are correlated with disease activity and possess a direct pathogenic role. ${ }^{35} 36$

The prerequisite for $\mathrm{B}$ cells to react to IL-7 stimulation is the re-expression of IL-7R on mature B cells. IL-7R is downregulated at the pre- $\mathrm{B}$ cell stage and expression of the receptor on mature, non-malignant $\mathrm{B}$ cells has only been reported in a few studies. ${ }^{3-5} \mathrm{It}$ had been suggested that CD40-induced activation in the germinal centre promotes IL-7R $\alpha$ re-expression which contributes to B cell receptor editing by re-inducing recombination-activating-genes proteins. ${ }^{4}$ We show that anti-CD40 independent of INF $\gamma$ or IL-4 and lipopolysaccharide, a TLR4 ligand, increases IL-7R $\alpha$ expression. Therefore, IL-7R re-expression can be induced by T-dependent and T-independent activating stimuli and might be a general feature of some activated B cells. Supporting this hypothesis, OA and RA patients show the same percentage of IL-7R+ B cells in synovial infiltrates, although B cell activation occurs in different ways in the two diseases.

IL-7R+ B cells might therefore be part of every inflammatory infiltrate independent of the cause, thus, non-specific in RA. Due to increased total cell number in RA as compared with OA tissue, the absolute numbers of IL-7R-expressing B cells are significantly increased in RA as compared with OA, which confirms the results from a recent study. ${ }^{3}$ Together with the data presented above and supporting many other studies, ${ }^{3} \quad 6 \quad 1017 \quad 1830$ the IL-7/IL-7R system might be a valuable drug target.

In addition, the present data show that treatment of CIA mice with activated B cells exposed to norepinephrine during activation leads to more severe arthritis and increased anti-CII autoantibodies. It has been demonstrated in several reports before that Th2-dependent antibody production is augmented following $\beta 2 \mathrm{AR}$ stimulation on $\mathrm{B}$ cells (reviewed in ${ }^{21}$ ). This is the first report to show that Th1-dependent autoantibody production in CIA is augmented by adrenergic stimulation of $\mathrm{B}$ cells. However, because the activation of $\mathrm{B}$ cells in vitro is polyclonal, the augmentation of the anti-CII response might not solely be explained by increased production from $\mathrm{B}$ cells that were exposed to norepinephrine in vitro but rather indirectly by promoting autoreactive B cells in vivo.

When B cells were exposed to norepinephrine and subsequently stimulated with IL-7, a further increase in proinflammatory action was expected. However, these B cells lose their proinflammatory effect and show anti-inflammatory potential, because they inhibit the proinflammatory capacity of norepinephrine treated B cells, and concomitantly show decreased ability to stimulate anti-CII antibody production. The loss of proinflammatory activity of IL-7 stimulated B cells goes along with a decreased phosphorylation of STAT5 following IL-7 stimulation in terbutaline-exposed cells. The $\beta 2 \mathrm{AR}$ stimulus interferes with proper downstream IL7R $\alpha$-signalling because STAT5 total protein content was unchanged in terbutaline-exposed B cells (data not shown).

There is no known interaction between the $\beta 2 \mathrm{AR}$ and IL-7R signalling pathways. One could speculate that negative regulators of pSTAT5, like suppressor of cytokine signalling- $1,{ }^{37}$ or $\mathrm{CD} 45^{38}$ are upregulated by $\beta 2 \mathrm{AR}$ signalling, but this is yet to be shown. Among others, phosphatidyl-inositol-3 kinasedependent, ${ }^{39}$ protein tyrosin kinase 2-dependent and mitogen activated protein kinase p38-dependent pathways ${ }^{40}$ have been suggested downstream of IL-7R in addition to STAT5 and might also be candidates for mediators of this effect. Which one of these pathways is used in norepinephrine pretreated B cells needs to be determined in future studies.

Taken together, the present results demonstrate a proinflammatory role for IL-7R + B cells in arthritis given the prerequisite that $B$ cells have not been activated in the presence of sympathetic neurotransmitters. Usually, B cells in lymphoid organs are exposed to sympathetic neurotransmitters, ${ }^{21} 32$ which would render IL-7R expressing B cells inert to stimulation by IL-7, at least in terms of STAT5-dependent mechanisms.

Vice versa, IL-7R+ B cells activated in the absence of sympathetic neurotransmitters act proinflammatory in CIA, a situation which occurs in inflamed synovial tissues in RA, where sympathetic nerve fibres are $\operatorname{lost}^{29}$ and ectopic germinal centres with local B cell activation occur. ${ }^{17}{ }^{41}$ Additionally, IL-7 is present in inflamed RA tissue and synovial fluid. ${ }^{11-15}$ Therefore, B cells activated in inflamed joints in the absence of sympathetic neurotransmitters might propagate inflammation in response to IL-7. Whether or not inhibition or modulation of IL-7 signalling via adrenergic stimuli also occurs in T cells needs to be determined (usually more IL-7R expression in T cells). In conclusion, the present data support the hypothesis that the IL-7/IL-7R system might be a valuable target in arthritis and underscores the importance of the SNS in regulating inflammatory processes.

Acknowledgements This study was funded by the institution and by the Deutsche Forschungsgemeinschaft (DFG FOR696, P0801/4-1).

Contributors GP study design, data acquisition, statistical data analysis, data interpretation, manuscript preparation; JA and MM study design, data acquisition; SA data acquisition, substantial manuscript revision; SG and RHS data interpretation, substantial manuscript revision.

Funding German Research Foundation (DFG FOR696, P0801/4-1).

Competing interests None.

Patient consent Obtained.

Ethics approval Ethics committee of the University of Regensburg.

Provenance and peer review Not commissioned; externally peer reviewed.

\section{REFERENCES}

1 Grabstein KH, Waldschmidt TJ, Finkelman FD, et al. Inhibition of murine B and T lymphopoiesis in vivo by an anti-interleukin 7 monoclonal antibody. J Exp Med 1993; 178:257-64.

2 Sudo T, Nishikawa S, Ohno N, et al. Expression and function of the interleukin 7 receptor in murine lymphocytes. Proc Natl Acad Sci USA 1993;90:9125-9.

3 Hartgring SA, van Roon JA, Wenting-van WM, et al. Elevated expression of interleukin-7 receptor in inflamed joints mediates interleukin-7-induced immune activation in rheumatoid arthritis. Arthritis Rheum 2009;60:2595-605.

4 Hikida M, Nakayama Y, Yamashita Y, et al. Expression of recombination activating genes in germinal center B cells: involvement of interleukin 7 (IL-7) and the IL-7 receptor. J Exp Med 1998;188:365-72.

5 Shibata H, Tani-ichi S, Lee HC, et al. Induction of the IL-7 receptor alpha chain in mouse peripheral B cells by glucocorticoids. Immunol Lett 2007;111:45-50.

6 Badot V, Durez P, Van den Eynde BJ, et al. Rheumatoid arthritis synovial fibroblasts produce a soluble form of the interleukin-7 receptor in response to pro-inflammatory cytokines. J Cell Mol Med 2011;15:2335-42. 
7 Goodwin RG, Friend D, Ziegler SF, et al. Cloning of the human and murine interleukin-7 receptors: demonstration of a soluble form and homology to a new receptor superfamily. Cell 1990;60:941-51.

8 Leonard WJ, Shores EW, Love PE. Role of the common cytokine receptor gamma chain in cytokine signaling and lymphoid development. Immunol Rev 1995;148:97-114.

9 Milne CD, Paige CJ. IL-7: a key regulator of B lymphopoiesis. Semin Immunol 2006:18:20-30.

10 Pickens SR, Chamberlain ND, Volin MV, et al. Characterization of interleukin-7 and interleukin-7 receptor in the pathogenesis of rheumatoid arthritis. Arthritis Rheum 2011:63:2884-93.

11 van Roon JA, Verweij MC, Wijk MW, et al. Increased intraarticular interleukin-7 in rheumatoid arthritis patients stimulates cell contact-dependent activation of CD4(+) T cells and macrophages. Arthritis Rheum 2005;52:1700-10.

12 van Roon JA, Glaudemans KA, Bijlsma JW, et al. Interleukin 7 stimulates tumour necrosis factor alpha and Th1 cytokine production in joints of patients with rheumatoid arthritis. Ann Rheum Dis 2003:62:113-19.

13 Harada S, Yamamura M, Okamoto $\mathrm{H}$, et al. Production of interleukin-7 and interleukin-15 by fibroblast-like synoviocytes from patients with rheumatoid arthritis. Arthritis Rheum 1999:42:1508-16.

14 Leistad L, Ostensen M, Faxvaag A. Detection of cytokine mRNA in human, articular cartilage from patients with rheumatoid arthritis and osteoarthritis by reverse transcriptase-polymerase chain reaction. Scand J Rheumatol 1998;27:61-7.

15 Shimaoka Y, Attrep JF, Hirano T, et al. Nurse-like cells from bone marrow and synovium of patients with rheumatoid arthritis promote survival and enhance function of human B cells. J Clin Invest 1998:102:606-18.

16 Tomita T, Takeuchi E, Toyosaki-Maeda T, et al. Establishment of nurse-like stromal cells from bone marrow of patients with rheumatoid arthritis: indication of characteristic bone marrow microenvironment in patients with rheumatoid arthritis. Rheumatology (Oxford) 1999:38:854-63.

17 Timmer TC, Baltus B, Vondenhoff $\mathrm{M}$, et al. Inflammation and ectopic lymphoid structures in rheumatoid arthritis synovial tissues dissected by genomics technology: identification of the interleukin-7 signaling pathway in tissues with lymphoid neogenesis. Arthritis Rheum 2007;56:2492-502.

18 Hartgring SA, Willis CR, Bijlsma JW, et al. Interleukin-7-aggravated joint inflammation and tissue destruction in collagen-induced arthritis is associated with T-cell and B-cell activation. Arthritis Res Ther 2012;14:R137.

19 Härle P, Möbius D, Carr DJ, et al. An opposing time-dependent immune-modulating effect of the sympathetic nervous system conferred by altering the cytokine profile in the local lymph nodes and spleen of mice with type II collagen-induced arthritis. Arthritis Rheum 2005;52:1305-13.

20 Pongratz G, Melzer M, Straub RH. The sympathetic nervous system stimulates anti-inflammatory B cells in collagen-type II-induced arthritis. Ann Rheum Dis 2012;71:432-9.

21 Sanders VM. The beta2-adrenergic receptor on T and B lymphocytes: do we understand it yet? Brain Behav Immun 2012;26:195-200.

22 Pongratz G, McAlees JW, Conrad DH, et al. The level of lgE produced by a B cell is regulated by norepinephrine in a p38 MAPK- and CD23-dependent manner. J Immunol 2006;177:2926-38.
23 Härle $\mathrm{P}$, Pongratz $\mathrm{G}$, Albrecht J, et al. An early sympathetic nervous system influence exacerbates collagen-induced arthritis via CD4+CD25+ cells. Arthritis Rheum 2008:58:2347-55.

24 Straub RH, Rauch L, Fassold A, et al. Neuronally released sympathetic neurotransmitters stimulate splenic interferon-gamma secretion from T cells in early type II collagen-induced arthritis. Arthritis Rheum 2008;58:3450-60.

25 Capellino S, Cosentino M, Wolff C, et al. Catecholamine-producing cells in the synovial tissue during arthritis: modulation of sympathetic neurotransmitters as new therapeutic target. Ann Rheum Dis 2010;69:1853-60.

26 Capellino S, Weber K, Gelder M, et al. First appearance and location of catecholaminergic cells during experimental arthritis and elimination by chemical sympathectomy. Arthritis Rheum 2012;64:1110-18.

27 Fassold A, Falk W, Anders S, et al. Soluble neuropilin-2, a nerve repellent receptor, is increased in rheumatoid arthritis synovium and aggravates sympathetic fiber repulsion and arthritis. Arthritis Rheum 2009;60:2892-901.

28 Krutzik PO, Nolan GP. Intracellular phospho-protein staining techniques for flow cytometry: monitoring single cell signaling events. Cytometry A 2003;55:61-70.

29 Miller LE, Justen HP, Scholmerich J, et al. The loss of sympathetic nerve fibers in the synovial tissue of patients with rheumatoid arthritis is accompanied by increased norepinephrine release from synovial macrophages. FASEB J 2000;14:2097-107.

30 Hartgring SA, Willis CR, Alcorn D, et al. Blockade of the interleukin-7 receptor inhibits collagen-induced arthritis and is associated with reduction of $T$ cell activity and proinflammatory mediators. Arthritis Rheum 2010;62:2716-25.

31 Pongratz G, Straub RH. Role of Peripheral Nerve Fibres in Acute and Chronic Inflammation in Arthritis. Nat Rev Rheum 2013:9:117-26.

32 Kohm AP, Tang Y, Sanders VM, et al. Activation of antigen-specific CD4+ Th2 cells and $B$ cells in vivo increases norepinephrine release in the spleen and bone marrow. J Immunol 2000;165:725-33.

33 Goetz CA, Harmon IR, O'Neil JJ, et al. STAT5 activation underlies IL7 receptor-dependent B cell development. J Immunol 2004;172:4770-8.

34 Lundström W, Fewkes NM, Mackall CL. IL-7 in human health and disease. Semin Immunol 2012;24:218-24.

35 Stuart JM, Dixon FJ. Serum transfer of collagen-induced arthritis in mice. J Exp Med 1983;158:378-92.

36 Terato K, Hasty KA, Reife RA, et al. Induction of arthritis with monoclonal antibodies to collagen. J Immunol 1992;148:2103-8.

37 Fujimoto M, Naka T, Nakagawa R, et al. Defective thymocyte development and perturbed homeostasis of T cells in STAT-induced STAT inhibitor-1/suppressors of cytokine signaling-1 transgenic mice. J Immunol 2000;165:1799-806.

38 Fleming HE, Milne CD, Paige CJ. CD45-deficient mice accumulate Pro-B cells both in vivo and in vitro. J Immunol 2004;173:2542-51.

39 Venkitaraman AR, Cowling RJ. Interleukin-7 induces the association of phosphatidylinositol 3-kinase with the alpha chain of the interleukin-7 receptor. Eur J Immunol 1994;24:2168-74.

40 Crawley JB, Rawlinson L, Lali FV, et al. T cell proliferation in response to interleukins 2 and 7 requires p38MAP kinase activation. J Biol Chem 1997;272:15023-7.

41 Weyand CM. Immunopathologic aspects of rheumatoid arthritis: who is the conductor and who plays the immunologic instrument? J Rheumatol Supp/ 2007;79:9-14. 
A RD IL-7 receptor $\alpha$ expressing B cells act proinflammatory in collagen-induced arthritis and are inhibited by sympathetic neurotransmitters

Georg Pongratz, Judith M Anthofer, Madlen Melzer, Sven Anders, Susanne Grässel and Rainer H Straub

Ann Rheum Dis 2014 73: 306-312 originally published online March 16, 2013

doi: 10.1136/annrheumdis-2012-202944

Updated information and services can be found at:

http://ard.bmj.com/content/73/1/306

\section{These include:}

References This article cites 41 articles, 16 of which you can access for free at: http://ard.bmj.com/content/73/1/306\#BIBL

Email alerting Receive free email alerts when new articles cite this article. Sign up in the service box at the top right corner of the online article.

Topic Articles on similar topics can be found in the following collections Collections

Degenerative joint disease (4641)

Musculoskeletal syndromes (4951)

Immunology (including allergy) (5144)

Osteoarthritis (931)

Connective tissue disease (4253)

Rheumatoid arthritis (3258)

\section{Notes}

To request permissions go to:

http://group.bmj.com/group/rights-licensing/permissions

To order reprints go to:

http://journals.bmj.com/cgi/reprintform

To subscribe to BMJ go to:

http://group.bmj.com/subscribe/ 